\title{
Development of Topical Niosomal Gel of Benzoyl Peroxide
}

\author{
Jigar Vyas, ${ }^{1,2}$ Puja Vyas, ${ }^{3}$ Dhaval Raval, ${ }^{2}$ and Paresh Paghdar ${ }^{2}$ \\ ${ }^{1}$ Pharmacy Department, The M. S. University of Baroda, G. H. Patel Building, Baroda, Gujarat 390002, India \\ ${ }^{2}$ Pharmaceutics Department, Sigma Institute of Pharmacy, Baroda, Gujarat 390022, India \\ ${ }^{3}$ Pharmaceutical Chemistry Department, Sigma Institute of Pharmacy, Baroda, Gujarat 390022, India \\ Correspondence should be addressed to Jigar Vyas, drjrvyas@yahoo.co.in
}

Received 5 April 2011; Accepted 30 April 2011

Academic Editors: N. Shukla and H. Tang

Copyright (C) 2011 Jigar Vyas et al. This is an open access article distributed under the Creative Commons Attribution License, which permits unrestricted use, distribution, and reproduction in any medium, provided the original work is properly cited.

\begin{abstract}
Benzoyl peroxide is macrolide antibiotic used commonly for the treatment of acne either alone or in combination. But it suffers from side effects like skin redness, irritation, itching, and edema. Niosomes, a nonionic surfactant vesicular formulation, have been explored extensively for topical application to enhance skin penetration as well as to improve skin retention of drugs. In the present study, Benzoyl peroxide was entrapped into niosomes by thin film hydration technique, and various process parameters were optimized by partial factorial design. The optimized niosomal formulation was incorporated into HPMC K15 gel and extensively characterized for percentage drug entrapment (PDE) and in vitro release performance. The stability of above formulation was studied at different temperatures. The present study demonstrated prolongation of drug release, increased drug retention into skin, and improved permeation across the skin after encapsulation of benzoyl peroxide into niosomal topical gel.
\end{abstract}

\section{Introduction}

Delivery of drug using vesicular carriers such as liposomes [1] and niosomes [2] have distinct advantages over conventional dosage forms because the vesicles can act as drugcontaining reservoirs. Modification of vesicle composition and/or surface can adjust the affinity for the target site and/or the drug release rate. The slowing drug release rate may reduce the toxicity of the drug. Hence, these carriers play an increasingly important role in drug delivery. Niosomes and liposomes are unilamellar or multilamellar vesicles wherein an aqueous phase is encapsulated in highly ordered bilayer made up of nonionic surfactant (niosomes) or lipid (liposomes) with or without other components like cholesterol and dicetyl phosphate [3]. Both delivery systems, niosomes and liposomes, possess more or less same advantage like desired interaction with human skin when applied through topical preparation by improving especially the horny layer characteristics, due to reduction in transdermal water loss and increase in smoothness via replenishing skin lipids [4]. Niosomes were preferred due to high cost and lower stability of lipids which have been replaced by nonionic surfactants. Niosomes loaded with drugs for dermal application show interactions with epidermal tissue without exerting immediate or strong systemic action [4]. Benzoyl peroxide is macrolide antibiotic which may be either bacteriostatic or bactericidal depending on the sensitivity of the microorganism and the concentration of the drug. Topical application of benzoyl peroxide often produces adverse effects like skin redness, irritation, itching, and so forth which leads to inconvenience and ignorance of therapy and results in no benefit or emergence of resistant strains of bacteria, sometimes. The present study is based on the hypothesis that incorporation of Benzoyl peroxide into niosomes will improve the amount and time of drug retention within the skin; which in turn will increase the therapeutic efficacy of the drug and reduce the toxicity.

\section{Materials and Methods}

2.1. Materials. Benzoyl peroxide, Span20, Span60, and Span80 were purchased from S. D. Fine Chemicals Ltd. (Mumbai, India), Cholesterol, chloroform, and methanol were purchased from Loba Chemie (Mumbai, India). All the reagents were used without further purifications. Phosphatebuffered saline pH 7.4 (PBS pH 7.4) and phosphate-Buffered Saline pH 6.8 (PBS pH 6.8) were prepared as described in the Indian Pharmacopoeia (1996), and necessary chemicals were obtained from the Loba Chem (Mumbai, India). All the chemicals used were of analytical reagent (AR) grade unless 
otherwise specified. Pernox gel (5\% benzoyl peroxide) was used as marketed formulation.

All necessary permissions from the ethical committee were procured before commencement of the study.

2.2. Preparation and Characterization of Niosomes. Niosomes were prepared by thin film hydration technique [5]. Thorough review of the literature gives numerous data on various parameters needed to be optimized, like type of nonionic surfactant, drug: cholesterol: surfactant ratio, solvent system, hydration volume, hydration temperature, hydration time, annealing time, film formation time, and so forth. The most critical parameters among these, type of surfactant, was optimized separately using full $2^{3}$ factorial design as shown in the Table 1.

The type of surfactant was optimized, keeping drug: cholesterol: surfactant molar ration at $1: 1: 1$, and all other parameters like Solvent system (chloroform: methanol, $1: 2$; $10 \mathrm{~mL})$, temperature of water bath $\left(60^{\circ} \mathrm{C}\right)$, vacuum for solvent evaporation $(20 \mathrm{mmHg})$, speed of rotation $(50 \mathrm{rpm})$, volume of hydration $(5 \mathrm{~mL})$, time of hydration $(1 \mathrm{hr})$ and annealing time $(1 \mathrm{hr})$ constant. The values of all these parameters were determined from thorough review of literature. The prepared niosomes loaded with benzoyl peroxide were analyzed for percentage drug entrapment (PDE) by colorimetric method using UV-Visible spectrometer (maximum absorption at $254 \mathrm{~nm}$ ) after separation of free drug as well as the particle size was analyzed by Malvern particle sizer, and d90 was taken as data and tabulated in different studies.

Hence, the final formulation would contain drug: cholesterol: surfactant at $1: 1: 1$ of either a surfactant alone or in combinations. In all further optimization study, all the parameters other than that considered for optimization were kept constant as per the values taken from literature or as optimized previously.

Batch F2 is successful batch and hence is carried forward for further optimization of combination of drug: cholesterol : surfactant molar ratio. The data was recorded in Table 2.

Batch NF13 was found to be the best combination of drug: cholesterol: surfactant $(1: 1.5: 3)$ and was used for all further study. Volume of hydration and time of hydration were optimized by using a $3^{2}$ factorial design model as tabulated below in Table 3 .

Other process parameters like speed of rotation, intensity of vacuum, temperature, and annealing time were optimized by using half $2^{4}$ factorial design as shown in Table 4 .

Finally, the solvent system was also optimized for proportion of both the solvents as well as total volume of solvents on the most successful batch NF22 and recorded in Table 5.

Final optimized batch (batch NF21) was then prepared repeatedly to check the reproducibility and to get final formulation in sufficient amount for further studies.

2.3. Preparation of HPMC K15 Gel. Sufficient quantity of HPMC K15 (2\% w/w) was weighed and sprinkled onto warm distilled water with continuous stirring. The dispersion was allowed to hydrate for 1-2 hours. Other ingredients like propylene glycol $(10 \% \mathrm{w} / \mathrm{w})$ and glycerol $(10 \% \mathrm{w} / \mathrm{w})$ were added subsequently to the aqueous dispersion with continuous stirring. A plain drug gel (Batch PG1) was prepared by adding required quantity of drug $(2 \% \mathrm{w} / \mathrm{w})$ and dispersed properly. The gel was sonicated for 30 minutes on bath sonicator and kept overnight to remove air bubbles. Niosomal gel (Batch NG2) was prepared by following the same procedure and adding niosomal cake containing an equivalent amount of drug instead of plain drug.

2.4. Drug-Leakage Study. Sufficient quantity of niosomal suspension (after removal of free drug) was sealed in $10 \mathrm{~mL}$ glass vial, and the niosomal gel formulation (Batch C2) was sealed in $10 \mathrm{gm}$ collapsible aluminum tube in triplicate and stored at refrigerated temperature $\left(2-8^{\circ} \mathrm{C}\right)$ and room temperature $\left(25 \pm 2^{\circ} \mathrm{C}\right)$. Specimen $(0.5 \mathrm{gm})$ from each sample was withdrawn at an interval of one week and analyzed for free drug content to determine the leakage rate. The results are recorded in Table 6 . The data were compared by applying ANOVA (single factor) at $P=.05$.

\subsection{In Vitro Permeation Studies}

2.5.1. Preparation of Membrane for In Vitro Studies. Human cadaver skin (HCS) was obtained and stored at $0^{\circ} \mathrm{C}$. A full thickness HCS membrane was prepared by shaving the skin, punching out a tissue of approximately $2.5 \mathrm{~cm}^{2}$ area with sharp blade, trimming away the excess fat, and slicing to about $450 \mathrm{~m}$ thickness. These slices were hydrated in $\mathrm{pH} 6.8$ phosphate buffer saline overnight prior to use [6].

The vertical type of Franz diffusion cell was designed, fabricated, and validated $[7,8]$ prior to diffusion study. $50 \mathrm{mg}$ of gel was applied on $2.00 \mathrm{~cm}^{2}$ area of epidermal surface of HCS tied to the lower end of donor compartment. The volume of the receptor compartment was kept $20 \mathrm{~mL}$. The cell was assembled in such a way that the dermal surface was just flushed to the surface of permeation fluid $(\mathrm{pH}$ 6.8 PBS) maintained at $37 \pm 1^{\circ} \mathrm{C}$ and stirred continuously on a magnetic stirrer at $50 \mathrm{rpm}$. Aliquots of $0.5 \mathrm{~mL}$ were withdrawn and analyzed for the drug content after suitable dilutions by colorimetric method. The volume of fluid was replaced with the same volume of fresh buffer after each sampling. The cumulative percentage drug diffused across the HCS was calculated at each sampling point and recorded in Table 7.

Amount of drug retained in the skin was calculated by subtracting the amount of free drug content in the receptor compartment and the amount of drug remained on the epidermal surface of skin from the initial drug content of the formulation applied, and results were recorded in Table 7. All the determinations were carried out in triplicate, and the data were compared by ANOVA $(P=.05)$.

\section{Results and Discussion}

Amongst many reported methods for the preparation of niosomes, thin film hydration technique was selected as it is the most documented method with greater entrapment efficiency and smaller particle size. An intense review of 
TABLE 1: Table shows optimization experiments for selection of surfactant.

\begin{tabular}{|c|c|c|c|c|c|}
\hline $\begin{array}{l}\text { Formulation } \\
\text { Code }\end{array}$ & Span 20 & Span 60 & Span 80 & $\begin{array}{c}\text { Percentage drug } \\
\text { entrapments } \pm \% \text { SD }\end{array}$ & $\begin{array}{c}\text { Average particle } \\
\text { size } \pm \% S D\end{array}$ \\
\hline NF1 & $1: 0(-1)$ & $1: 0(-1)$ & $1: 0(-1)$ & \multicolumn{2}{|c|}{ No niosomes without surfactant } \\
\hline NF2 & $1: 0(-1)$ & $1: 0(-1)$ & $1: 1(+1)$ & $82.26 \%( \pm 1.89)$ & $4.67( \pm 0.088)$ \\
\hline NF3 & $1: 0(-1)$ & $1: 1(+1)$ & $1: 0(-1)$ & $52.55 \%( \pm 1.65)$ & $6.87( \pm 0.317)$ \\
\hline NF4 & $1: 0(-1)$ & $1: 1(+1)$ & $1: 1(+1)$ & $70.62 \%( \pm 2.25)$ & $3.39( \pm 0.078)$ \\
\hline NF5 & $1: 1(+1)$ & $1: 0(-1)$ & $1: 0(-1)$ & $29.23 \%( \pm 0.96)$ & $6.87( \pm 0.317)$ \\
\hline NF6 & $1: 1(+1)$ & $1: 0(-1)$ & $1: 1(+1)$ & $49.51 \%( \pm 1.35)$ & $6.13( \pm 0.199)$ \\
\hline NF7 & $1: 1(+1)$ & $1: 1(+1)$ & $1: 0(-1)$ & $39.19 \%( \pm 1.28)$ & $4.13( \pm 0.170)$ \\
\hline NF8 & $1: 1(+1)$ & $1: 1(+1)$ & $1: 1(+1)$ & $47.95 \%( \pm 1.96)$ & $6.87( \pm 0.317)$ \\
\hline
\end{tabular}

$n=3$; the two levels of study $-1=1: 0$ and $+1=1: 1$ are in the form of drug : surfactant molar ratio.

TABLE 2: Table contains data of optimization of surfactant: cholesterol ratio.

\begin{tabular}{|c|c|c|c|c|c|}
\hline $\begin{array}{l}\text { Formulation } \\
\text { code }\end{array}$ & Drug & Cholesterol & Span 80 & $\begin{array}{c}\text { Percentage drug } \\
\text { entrapments } \pm \% \mathrm{SD}\end{array}$ & $\begin{array}{c}\text { Average particle } \\
\text { size } \pm \% S D\end{array}$ \\
\hline NF9 & 1 & 1 & 1 & $82.26 \%( \pm 1.89)$ & $4.67( \pm 0.08)$ \\
\hline NF10 & 1 & 1 & 2 & $86.35 \%( \pm 2.77)$ & $4.51( \pm 0.31)$ \\
\hline NF11 & 1 & 2 & 1 & $56.55 \%( \pm 1.98)$ & $5.23( \pm 0.22)$ \\
\hline NF12 & 1 & 2 & 2 & $72.02 \%( \pm 3.25)$ & $6.68( \pm 0.08)$ \\
\hline NF13 & 1 & 1.5 & 3 & $89.74 \%( \pm 1.87)$ & $4.13( \pm 0.31)$ \\
\hline
\end{tabular}

$n=3$; batch F2 was taken, and experiments were conducted by varying the proportion of cholesterol and surfactant.

TABLE 3: Table explains optimization of volume of hydration and time of hydration.

\begin{tabular}{lcccc}
\hline $\begin{array}{l}\text { Formulation } \\
\text { code }\end{array}$ & $\begin{array}{c}\text { Volume of } \\
\text { hydration }\end{array}$ & $\begin{array}{c}\text { Time of } \\
\text { hydration }\end{array}$ & $\begin{array}{c}\text { Percentage drug } \\
\text { entrapments } \pm \% \text { SD }\end{array}$ & $\begin{array}{c}\text { Average particle size } \\
\pm \% \text { SD }\end{array}$ \\
\hline NF13 & $3(-1)$ & $0.5(-1)$ & $70.05 \%( \pm 0.80)$ & $7.77( \pm 0.31)$ \\
NF14 & $3(-1)$ & $1.0(0)$ & $75.26 \%( \pm 2.39)$ & $4.67( \pm 0.09)$ \\
NF15 & $3(-1)$ & $2.0(+1)$ & $79.55 \%( \pm 2.10)$ & $6.87( \pm 0.32)$ \\
NF16 & $5(0)$ & $0.5(-1)$ & $70.62 \%( \pm 2.25)$ & $3.39( \pm 0.08)$ \\
NF17 & $5(0)$ & $1.0(0)$ & $82.26 \%( \pm 1.89)$ & $4.67( \pm 0.08)$ \\
NF18 & $5(0)$ & $2.0(+1)$ & $88.51 \%( \pm 1.30)$ & $4.11( \pm 0.19)$ \\
NF19 & $7(+1)$ & $0.5(-1)$ & $69.19 \%( \pm 1.88)$ & $4.13( \pm 0.17)$ \\
NF20 & $7(+1)$ & $1.0(0)$ & $77.95 \%( \pm 1.96)$ & $6.87( \pm 0.30)$ \\
NF21 & $7(+1)$ & $2.0(+1)$ & $92.12 \%( \pm 2.43)$ & $4.78( \pm 0.09)$ \\
\hline
\end{tabular}

$n=3$; batch NF13 was taken with all other parameter constant except parameters shown above.

TABLE 4: Table reflects data of optimization of speed of rotation, intensity of vacuum, temperature, and annealing time.

\begin{tabular}{|c|c|c|c|c|c|c|}
\hline $\begin{array}{l}\text { Formulation } \\
\text { code }\end{array}$ & $\begin{array}{c}\text { Speed of } \\
\text { rotation }(\mathrm{rpm})\end{array}$ & $\begin{array}{l}\text { Intensity of } \\
\text { vacuum } \\
(\mathrm{mmHg})\end{array}$ & $\begin{array}{c}\text { Temperature } \\
\left({ }^{\circ} \mathrm{C}\right)\end{array}$ & $\begin{array}{l}\text { Annealing time } \\
\text { (Hour) }\end{array}$ & $\begin{array}{l}\text { Percentage drug } \\
\text { Entrapments } \\
\pm \% \mathrm{SD}\end{array}$ & $\begin{array}{l}\text { Average particle } \\
\text { size } \pm \% S D\end{array}$ \\
\hline NF21 & $50(-1)$ & $20(-1)$ & $60(-1)$ & $1(-1)$ & $92.16 \%( \pm 2.43)$ & $4.78( \pm 0.09)$ \\
\hline NF22 & $75(+1)$ & $25(+1)$ & $60(-1)$ & $1(-1)$ & $79.67 \%( \pm 1.27)$ & $6.67( \pm 0.22)$ \\
\hline NF23 & $75(+1)$ & $20(-1)$ & $70(+1)$ & $1(-1)$ & $80.11 \%( \pm 3.31)$ & $7.81( \pm 0.32)$ \\
\hline NF24 & $75(+1)$ & $20(-1)$ & $60(-1)$ & $2(+1)$ & $89.55 \%( \pm 3.90)$ & $2.43( \pm 0.03)$ \\
\hline NF25 & $50(-1)$ & $25(+1)$ & $70(+1)$ & $1(-1)$ & $77.34 \%( \pm 2.88)$ & $5.66( \pm 0.11)$ \\
\hline NF26 & $50(-1)$ & $25(+1)$ & $60(-1)$ & $2(+1)$ & $81.14 \%( \pm 2.11)$ & $5.22( \pm 0.14)$ \\
\hline NF27 & $70(-1)$ & $20(-1)$ & $70(+1)$ & $2(+1)$ & $80.12 \%( \pm 3.78)$ & $4.06( \pm 0.16)$ \\
\hline NF28 & $75(+1)$ & $25(+1)$ & $70(+1)$ & $2(+1)$ & $75.54 \%( \pm 2.21)$ & $4.43( \pm 0.13)$ \\
\hline
\end{tabular}

$n=3$; batch NF21 was taken and optimized for the abovementioned variables. 
TABLE 5: Table shows data of optimization of solvent system.

\begin{tabular}{lccccc}
\hline $\begin{array}{l}\text { Formulation } \\
\text { code }\end{array}$ & Chloroform & Methanol & $\begin{array}{c}\text { Volume of solvent } \\
\text { system }\end{array}$ & $\begin{array}{c}\text { Percentage drug } \\
\text { entrapments } \pm \% \text { SD }\end{array}$ & $\begin{array}{c}\text { Average particle } \\
\text { size } \pm \% S D\end{array}$ \\
\hline NF29 & 1 & 1 & 10 & $82.26 \%( \pm 1.89)$ & $4.67( \pm 0.09)$ \\
NF30 & 2 & 1 & 10 & $56.55 \%( \pm 1.98)$ & $5.23( \pm 0.21)$ \\
NF21 & 1 & 2 & 10 & $92.16 \%( \pm 2.43)$ & $4.78( \pm 0.09)$ \\
NF31 & 1 & 2 & 5 & $72.02 \%( \pm 3.25)$ & $6.68( \pm 0.08)$ \\
NF32 & 1 & 2 & 20 & $80.35 \%( \pm 2.77)$ & $7.51( \pm 0.33)$ \\
\hline
\end{tabular}

$n=3$; Batch F21 was taken and studied for the best solvent system to get maximum PDE.

TABLE 6: Table contains data of drug leakage study at RT and refrigerated temperature.

\begin{tabular}{|c|c|c|c|c|}
\hline \multirow{3}{*}{ Time in weeks } & \multicolumn{4}{|c|}{ Percentage drug retained $( \pm S D)$} \\
\hline & \multicolumn{2}{|c|}{ Niosomal suspension } & \multicolumn{2}{|c|}{ Niosomal gel of Carbopol } \\
\hline & $4^{\circ} \mathrm{C}(\mathrm{NS})$ & RT (NS) & $4^{\circ} \mathrm{C}(\mathrm{NG})$ & RT (NG) \\
\hline 1 & $98.90( \pm 3.74)$ & $89.11( \pm 3.33)$ & $99.89( \pm 3.26)$ & $94.20( \pm 2.72)$ \\
\hline 2 & $97.30( \pm 3.67)$ & $78.83( \pm 3.41)$ & $99.22( \pm 2.11)$ & $87.09( \pm 3.92)$ \\
\hline 3 & $95.89( \pm 3.16)$ & $68.22( \pm 2.98)$ & $98.73( \pm 3.94)$ & $81.82( \pm 3.16)$ \\
\hline 4 & $93.55( \pm 2.71)$ & $61.19( \pm 2.86)$ & $98.32( \pm 4.02)$ & $76.90( \pm 3.57)$ \\
\hline 5 & $89.48( \pm 1.76)$ & $54.40( \pm 1.99)$ & $98.02( \pm 3.65)$ & $72.10( \pm 1.78)$ \\
\hline 6 & $86.88( \pm 1.24)$ & $46.21( \pm 1.32)$ & $97.77( \pm 2.83)$ & $68.89( \pm 2.78)$ \\
\hline 7 & $82.77( \pm 2.43)$ & $39.11( \pm 0.74)$ & $97.56( \pm 1.98)$ & $65.11( \pm 2.67)$ \\
\hline 8 & $78.92( \pm 0.74)$ & $33.38( \pm 0.43)$ & $97.38( \pm 2.87)$ & $61.08( \pm 1.96)$ \\
\hline 9 & $75.45( \pm 1.17)$ & $28.39( \pm 1.15)$ & $97.22( \pm 3.49)$ & $58.12( \pm 1.14)$ \\
\hline 10 & $73.29( \pm 1.87)$ & $23.45( \pm 1.07)$ & $97.07( \pm 2.67)$ & $56.23( \pm 1.08)$ \\
\hline 11 & $70.67( \pm 2.87)$ & $20.04( \pm 0.56)$ & $96.97( \pm 1.10)$ & $53.55( \pm 1.17)$ \\
\hline 12 & $65.89( \pm 1.65)$ & $17.12( \pm 0.48)$ & $96.85( \pm 2.26)$ & $51.07( \pm 2.22)$ \\
\hline
\end{tabular}

$n=3$; RT: room temperature $\left(25 \pm 2^{\circ} \mathrm{C}\right)$; NS: niosomal suspension; NG: niosomal gel.

TABLe 7: Table shows data of diffusion study of drug across human cadaver skin (HCS).

\begin{tabular}{lccc}
\hline Time in hours & Batch $\mathrm{C}_{1}$ & $\begin{array}{c}\text { Percentage drug release }( \pm \mathrm{SD}) \\
\text { Batch } \mathrm{C}_{2}\end{array}$ & - \\
\hline 0.5 & - & - & $9.98( \pm 0.27)$ \\
1 & $07.97( \pm 0.54)$ & $09.24( \pm 1.20)$ & $18.84( \pm 0.67)$ \\
2 & $17.34( \pm 0.89)$ & $15.11( \pm 1.86)$ & $26.33( \pm 0.91)$ \\
3 & $24.45( \pm 0.76)$ & $21.76( \pm 1.13)$ & $39.08( \pm 1.40)$ \\
5 & $36.63( \pm 1.94)$ & $28.83( \pm 2.09)$ & $51.23( \pm 1.34)$ \\
8 & $48.43( \pm 2.35)$ & $32.31( \pm 2.34)$ & $63.67( \pm 2.89)$ \\
12 & $59.42( \pm 3.01)$ & Percentage drug retained into human cadaver skin (HCS) after 12 hours & $24.88( \pm 0.49)$ \\
\hline & & $41.53( \pm 1.75)$ &
\end{tabular}

literature reveals that Tweens show poor entrapment with lipophilic or amphiphilic drugs whereas Spans give higher entrapment with high stability. This is due to the fact that hydrophilic surfactants (Tweens) owing to high aqueous solubility do not form proper vesicular structure in aqueous medium, whereas due to lipophilic in nature, Spans form vesicles and entrap the lipophilic drug or amphiphilic drugs. Table 1 reveals that Span 80 alone gave the highest entrapment $(82.26 \%)$ which decreased when combined with either Span $20(49.51 \%)$ or Span 60 (70.62\%). Data of Table 2 suggests that the PDE decreased from $89.74 \%$ to $56.55 \%$ as the proportion of cholesterol increased from $27 \%(1: 1.5: 3)$ to $50 \%(1: 2: 1)$. This indicates that the characteristics of Cholesterol of decreasing leakage of bilayer structure and producing surface smoothness diminish at higher proportions as it imparts crystallinity to the bilayer 
TABLE 8: Table shows final optimized batch.

\begin{tabular}{lcc}
\hline $\begin{array}{l}\text { Serial } \\
\text { No. }\end{array}$ & Parameters & Optimized value \\
\hline 1 & Nonionic surfactant & Span 80 \\
2 & Drug : cholesterol : surfactant & $1: 1.5: 3$ \\
& molar ratio & Chloroform $:$ methanol, \\
3 & Solvent system & $1: 2$ \\
4 & Hydration temperature & $60^{\circ} \mathrm{C}$ \\
5 & Vacuum & $20 \mathrm{mmHg}$ \\
6 & Speed of rotation & $50 \mathrm{rpm}$ \\
7 & Hydration volume & $7 \mathrm{~mL}$ \\
8 & Hydration time & $2 \mathrm{hour}$ \\
9 & Annealing time & $1 \mathrm{hour}$ \\
\hline
\end{tabular}

$[9,10]$. Other parameters were also optimized as recorded in Tables 3, 4, and 5 to get the final optimized formulation which was recorded in Table 8 .

Analysis of data of drug leakage study by applying ANOVA reveals that niosomal drug gel is significantly more stable as compared niosomal suspension and also both formulations are significantly more stable at refrigerated temperature than room temperature, as it is observed in Figure 1. The reason behind higher leakage at higher temperature may be the higher fluidity of lipid bilayer at higher 11 temperature $[11,12]$. The stability of niosomes improved after incorporation into gel base may be due to prevention of fusion of niosomes.

The data of the in vitro drug release study suggests that all the formulations followed Higuchi's diffusion-controlled model. When the data was compared by ANOVA test (single factor, $P=.05$ ), it revealed a significant difference in drug release rate between niosomal gel and plain drug gel. The data of drug retention into skin after 24 hours have shown maximum drug retention (41.53\%) with niosomal gel (Batch $\mathrm{C} 2)$ as compared to plain drug gel (21.45\%) and marketed gel (24.88\%).

Figure 2 revealed that prolonged drug release was observed during in vitro diffusion study across human cadaver skin from niosomal benzoyl peroxide gel as compared to plain drug gel and market preparation which may be due to slower diffusion of drug into the skin and creation of reservoir effect for drug in the skin. The other components of niosomes, that is, surfactant and cholesterol also deposit along with drug into the skin and thereby increasing the drug retention capacity into skin.

\section{Conclusion}

The finding of this investigation has conclusively demonstrated that encapsulation of benzoyl peroxide into niosomal gel formulation improved skin retention which may be reflected, based on prior hypothesis, as significantly improved therapeutic response and considerably reduced adverse symptoms. However, the role of niosomal Benzoyl peroxide gel of this study can only be settled after clinical

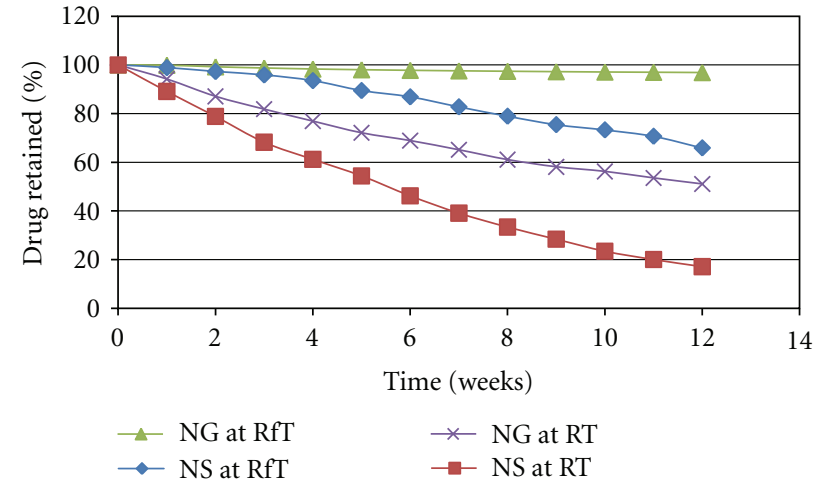

Figure 1: Drug leakage study at room temperature, and refrigerated temperature NG at RfT: Niosomal Gel at Refrigerated Temperature; NS at RfT: niosomal suspension at refrigerated temperature; NG at RT: niosomal gel at room temperature; NS at RT: niosomal suspension at room temperature.

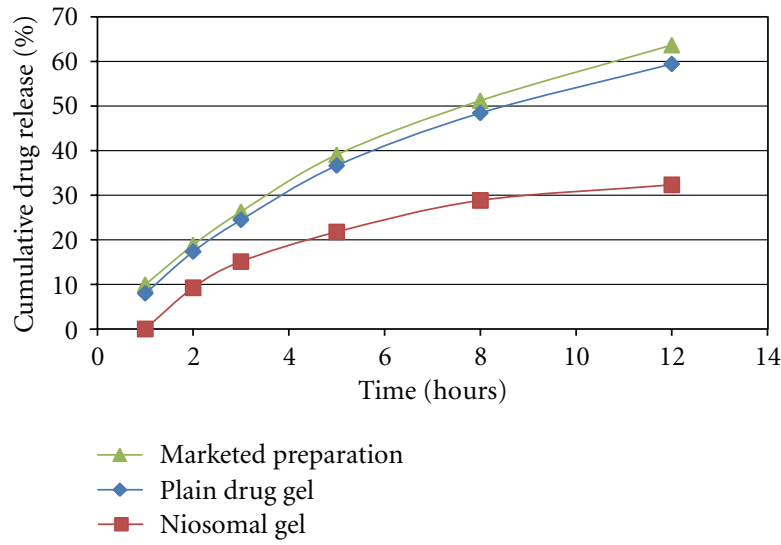

FIgure 2: Diffusion study of drug across human cadaver skin (HCS).

evaluation of the product with large number of patients with special focus on the adverse symptoms of the therapy.

\section{Conflict of Interests}

The authors Declare that there is no conflict of interest.

\section{References}

[1] G. Betageri and M. Habib, "Liposomes as drug carriers," Journal of Biomedical \& Pharmaceutical Engineering, vol. 14, pp. 76-77, 1994.

[2] H. Schreier and J. A. Bouwstra, "Liposomes and niosomes as topical drug carriers: dermal and transdermal drug delivery," Journal of Controlled Release, vol. 30, no. 1, pp. 1-15, 1994.

[3] A. Namdeo and N. K. Jain, "Niosomes as drug carriers," Indian Journal of Pharmaceutical Sciences, vol. 58, no. 2, pp. 41-46, 1996.

[4] H. E. Junginger, H. E. J. Hofland, and J. A. Bouwstra, "Liposomes and niosomes interaction with human skin," Cosmetics \& Toiletries, vol. 106, pp. 45-50, 1991. 
[5] M. N. Azmin, A. T. Florence, R. M. Handjani-Vila, J. F. B. Stuart, G. Vanlerberghe, and J. S. Whittaker, "The effect of non-ionic surfactant vesicle (niosome) entrapment on the absorption and distribution of methotrexate in mice," Journal of Pharmacy and Pharmacology, vol. 37, pp. 237-242, 1985.

[6] H. E. J. Hofland, R. Vandergest, H. E. Bodde, H. E. Junginger, and J. A. Bouwstra, "Estradiol permeation from non ionic surfactant vesicles through human stratum corneum in-vitro," Pharmaceutical Research, vol. 11, pp. 659-664, 1994.

[7] D. R. Friend, "In vitro permeation techniques," Journal of Controlled Release, vol. 18, no. 3, pp. 235-248, 1992.

[8] K. Tojo, "Design and calibration of in-vitro permeation apparatus," in Transdermal Controlled Systemic Medications, Y. W. Chien, Ed., pp. 127-158, Marcel Dekker, New York, NY, USA, 1987.

[9] I. F. Uchegbu and S. P. Vyas, "Non ionic surfactant based vesicles in drug delivery," International Journal of Pharmaceutics, vol. 172, no. 1-2, pp. 33-70, 1998.

[10] A. J. Baillie, A. T. Florence, L. R. Hume, G. T. Muirhead, and A. Rogerson, "The preparation and properties of non ionic surfactant vesicles," The Journal of pharmacy and pharmacology, vol. 37, no. 12, pp. 863-868, 1985.

[11] S. Bhaskaran and L. Panigrah, "Formulation and evaluation of niosomes using different non ionic surfactants," Indian Journal of Pharmaceutical Sciences, vol. 1, pp. 63-65, 2002.

[12] H. Jousma, J. G. H. Joosten, and H. E. J. Jumgimger, "Mesophases in mixtures of water and polyoxyethylene surfactant: Variations of repeat spacing with temperature and composition," Colloid \& Polymer Science, vol. 266, no. 7, pp. 640-651, 1988. 

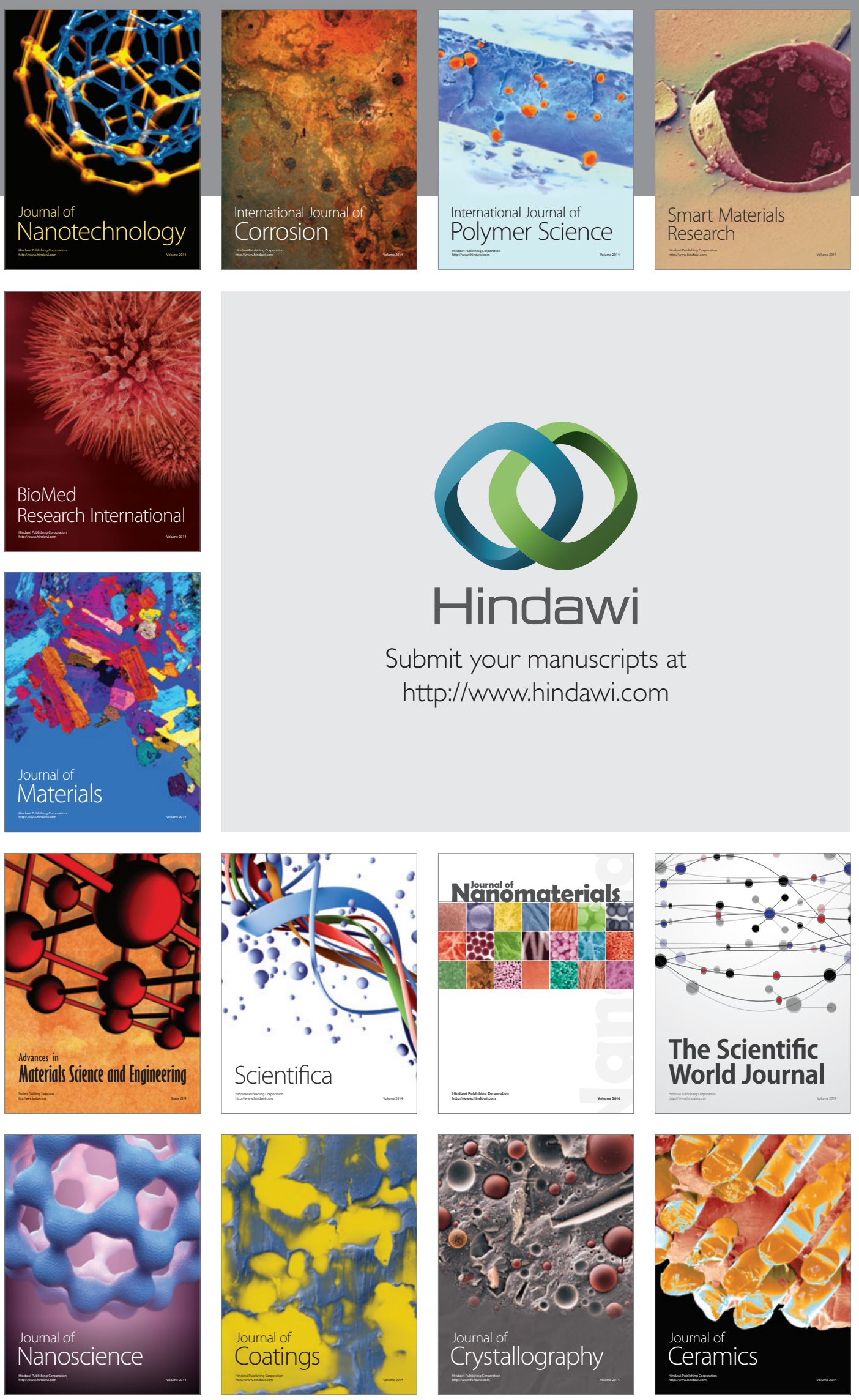

The Scientific World Journal

Submit your manuscripts at

http://www.hindawi.com

\section{World Journal}

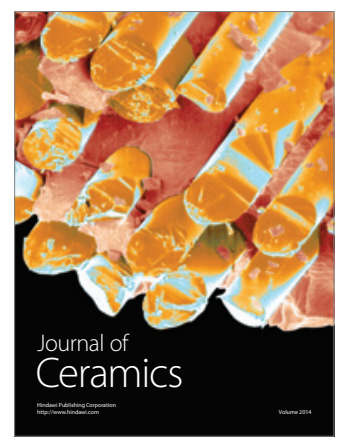

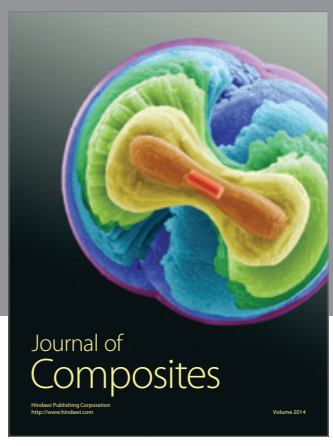
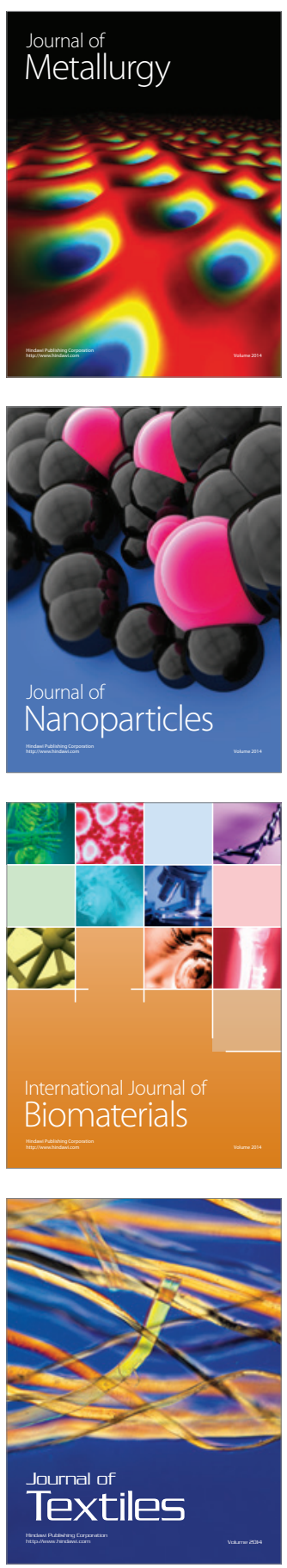